\title{
Local myalgia compared to myofascial pain with referral according to the DC/TMD: Axis I and II results
}

\author{
Orit Winocur-Arias ${ }^{1 \dagger}$, Pessia Friedman-Rubin ${ }^{2+}$, Kian Abu Ras ${ }^{3,4}$, Larry Lockerman ${ }^{1}$, Alona Emodi-Perlman²,
} Tzvika Greenbaum ${ }^{5}$ and Shoshana Reiter ${ }^{1 *}$

\begin{abstract}
Background: The Diagnostic Criteria for Temporomandibular Disorders (DC/TMD) categorized TMD muscle disorders into 3 subgroups: local myalgia, myofascial pain with spreading and myofascial pain with referral. However, the rationale for such division into subgroups and the pathogenesis and prognosis of muscle-related TMD are still poorly understood. The aim of this study was to explore the differences between local myalgia and myofascial pain with referral by means of a biopsychosocial model based on the DC/TMD.
\end{abstract}

Methods: This retrospective study included all consecutive TMD patients who were diagnosed according to the DC/ TMD in our institution between 2015 and 2018. The Axis I and II findings of patients diagnosed with local myalgia were compared to those of patients with myofascial pain with referral. A $p$ value $<0.05$ was considered statistically significant.

Results: A total of 255 patients (61 men and 194 women, mean age $37.8 \pm 15.34$ years) were enrolled into the study, 114 in the local myalgia group and 83 in the myofascial pain with referral group. The levels of depression and nonspecific physical symptoms, headache attributed to TMD (HAattrTMD), and characteristic pain intensity (CPI) were significantly higher in the latter group. The significant differences for depression and nonspecific physical symptoms persisted after excluding patients diagnosed with HAattrTMD, however, the levels of significance were lower ( $p=0.006$ compared to $p=0.033$ for depression total score, and $p=0.001$ compared to $p=0.046$ for nonspecific physical symptoms total score). CPI levels, extent of disability, and pain duration were similar for both groups when excluding for HAattrTMD.

Conclusion: The current study findings highlight the importance of differentiating between subgroups of myalgia according to the DC/TMD. The diagnosis of myofascial pain with referral may point to a significant Axis II component.

Keywords: DC/TMD, Myofascial pain with referral, Local myalgia, Axis II

*Correspondence: shoshana.reiter@gmail.com

${ }^{\dagger}$ Orit Winocur-Arias and Pessia Friedman-Rubin contributed equally to this article

1 Department of Oral Pathology, Oral Medicine, and Maxillofacial Imaging, The Maurice and Gabriela Goldschleger School of Dental Medicine, Sackler Faculty of Medicine, Tel Aviv University, Tel Aviv, Israel Full list of author information is available at the end of the article This study was undertaken in partial fulfillment of a DMD thesis at the Maurice and Gabriela Goldschleger Schoolof Dental Medicine, Tel Aviv University, Tel Aviv, Israel

\section{Background}

Temporomandibular disorders (TMD) are defined as "a group of musculoskeletal and neuromuscular conditions that involve the temporomandibular joints (TMJs), the masticatory muscles, all associated structures of mastication, and associated tissues" [1]. Diagnostic criteria based on a biopsychosocial model [the Research Diagnostic Criteria/TMD (RDC/TMD) and the newer version,

(c) The Author(s) 2022. Open Access This article is licensed under a Creative Commons Attribution 4.0 International License, which permits use, sharing, adaptation, distribution and reproduction in any medium or format, as long as you give appropriate credit to the original author(s) and the source, provide a link to the Creative Commons licence, and indicate if changes were made. The images or other third party material in this article are included in the article's Creative Commons licence, unless indicated otherwise in a credit line to the material. If material is not included in the article's Creative Commons licence and your intended use is not permitted by statutory regulation or exceeds the permitted use, you will need to obtain permission directly from the copyright holder. To view a copy of this licence, visit http://creativecommons.org/licenses/by/4.0/. The Creative Commons Public Domain Dedication waiver (http://creativeco mmons.org/publicdomain/zero/1.0/) applies to the data made available in this article, unless otherwise stated in a credit line to the data. 
the DC/TMD] enabled exploration of the association of both physical aspects (Axis I) and psychological factors (Axis II) in order to understand the development of cases of persistent TMD that are refractory to conventional treatment.

Muscle-related disorders represent the largest subgroup among the various TMD diagnoses [2]. The RDC/ TMD has included only one diagnosis of muscle-related disorders for research purposes, that of "myofascial pain with/without limited opening". Following the RDC/TMD validation project [3], the newer DC/TMD [4] revised portions of both the Axis I and Axis II components. One of the changes was the categorization of TMD muscle disorders into the 3 subgroups of local myalgia, myofascial pain with spreading, and myofascial pain with referral. Among them, local myalgia and myofascial pain with referral received acceptable levels of sensitivity and specificity for a definitive diagnosis (a sensitivity of $90 \%$ and a specificity of $99 \%$ for local myalgia, and a sensitivity of $86 \%$ and a specificity of $98 \%$ for myofascial pain with referral). However, neither diagnosis has been assessed for criterion validity [5].

The 2 diagnoses are closely related to jaw function and differ only by the ability to create local versus referred pain beyond the boundary of the muscle being palpated. As such, the basis for differentiating between them is purely clinical. It should be noted that although diagnostic criteria for all subgroups of muscle-related pain were established in the DC/TMD, the pathogenesis and prognosis of muscle-related TMD is still poorly understood. Several central and peripheral theories have attempted to explain the pathophysiology underlying myofascial pain with referral [6-9]. The pathophysiology underlying chronic local myalgia is unclear as well [10-13]. This uncertainty of the pathophysiology of muscle-related TMD is reflected in the first edition of the International Classification of Orofacial Pain (ICOP) which was recently released [14]. The authors of the ICOP proposed adherence to the single terminology of "myofascial" in order to reflect the yet undetermined etiology.

However, so far only few studies have examined the differences between local myalgia and myofascial pain with referral by applying the DC/TMD [15-17]. There are several studies on the differences in treatment response between the 2 diagnoses $[18,19]$. Other studies which used the DC/TMD did not differentiate between the different subgroups of muscle-related disorders [20, 21].

The current study was performed following the recommendation of the co-lead authors $[22,23]$ of the DC/ TMD [4] to determine whether there is any difference between the subgroups of myalgia according to the $\mathrm{DC} /$ TMD in terms of mechanisms and clinical implications. Therefore, the purpose of this study was to further explore the differences between local myalgia and myofascial pain with referral, as to Axis I and II of the DC/ TMD, according to the biopsychosocial model.

\section{Methods}

The study was approved by the Tel Aviv University Institutional Ethical Committee prior to data collection (\#14134_20180327). Informed consent was waived since the data were retrieved retrospectively. However, each patient who is referred to the "Orofacial and TMD Clinic" routinely signs a form in which s/he agrees that his/her data can be anonymously used for research purposes. The study was self-funded by the authors.

This retrospective study population included 558 consecutive patients who were seen for the first time in the Tel Aviv University Orofacial Pain Clinic during 20152018. All the patients were examined by senior staff members certified in the DC/TMD Training and Calibration Course at the Department of Orofacial Pain and Jaw Function at the Faculty of Odontology at Malmö University, Sweden. Each patient who was suspected as having TMD underwent a full DC/TMD Axis I and Axis II evaluation according to the official Hebrew version [24] of the DC/TMD [4]. The nonpainful Axis I diagnoses included intra-articular TMD (disc displacement with reduction, disc displacement with reduction with intermittent locking, disc displacement without reduction with limited opening, and disc displacement without reduction without limited opening), degenerative joint disease, and subluxation. Painful Axis I diagnoses included arthralgia, HAattrTMD, local myalgia, and myofascial pain with referral.

The following instruments were used to evaluate Axis II: depression level [Patient Health Questionnaire (PHQ)-9], nonspecific physical symptom levels (PHQ15 questionnaire for somatic symptoms), anxiety level [Generalized Anxiety Disorder (GAD)-7]. Characteristic pain intensity (CPI), pain persistence classification, and Graded Chronic Pain Scale (GCPS) version 2.0 were calculated for each patient according to the specifications of the DC/TMD. Excluded from the study were 56 patients who did not complete the DC/TMD questionnaire, 67 patients who were younger than 18 years, 142 patients who received other orofacial pain diagnoses that included systemic diseases (e.g., fibromyalgia and inflammatory arthritis), and 38 patients who did not meet the DC/TMD criteria for diagnosis of TMD, leaving a total 255 TMD patients. The final study population was comprised of 197 patients who received Axis I muscle-related diagnosis, 114 of whom were diagnosed as having local myalgia and 83 patients diagnosed as having myofascial pain with referral (Fig. 1). 


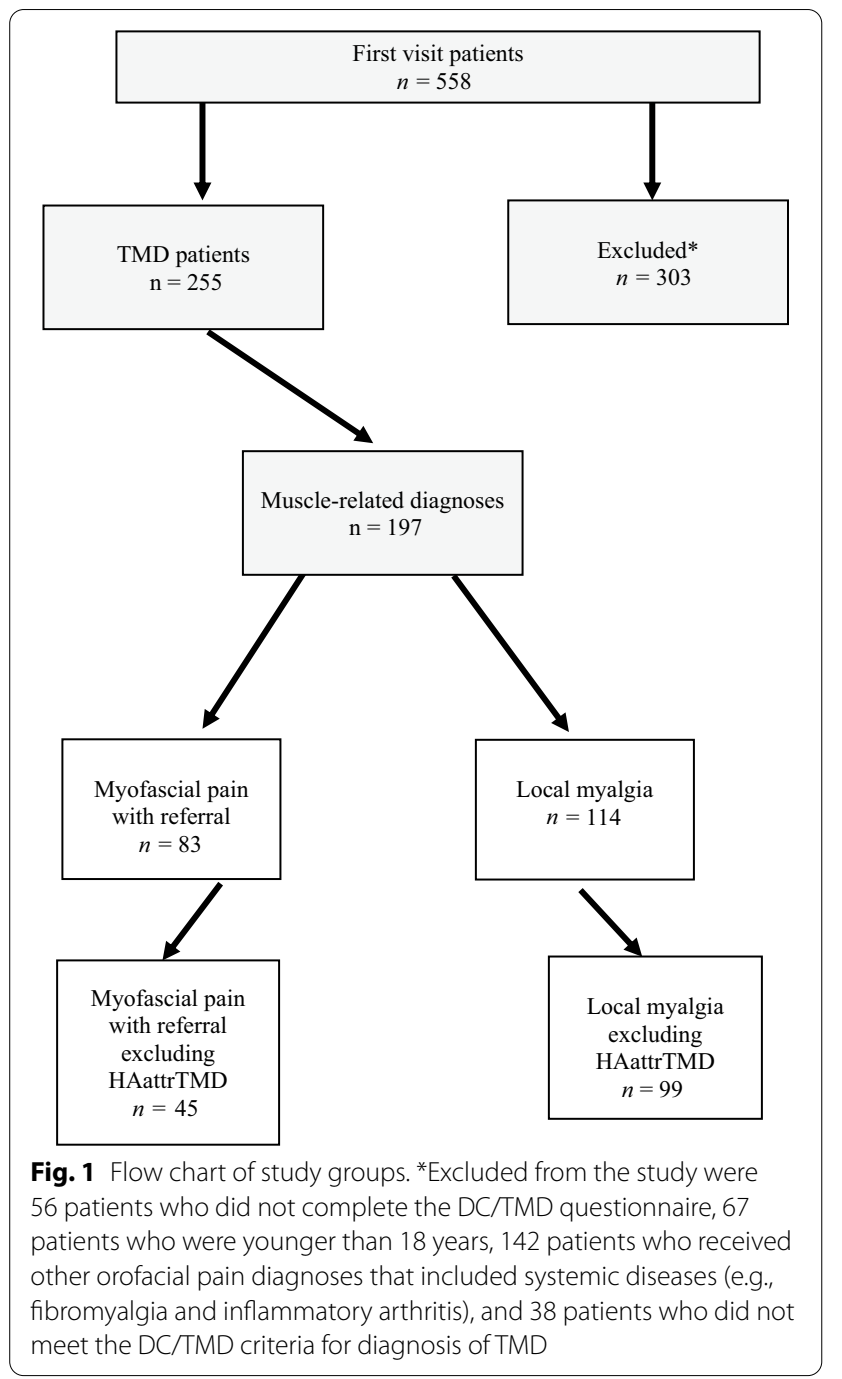

\section{Statistical analysis}

Continuous variables were evaluated for normal distribution by means of a histogram and Q-Q plots. Since the continuous variables did not distribute normally, they were reported as the median and interquartile range (IQR) and standard deviation (SD) and analyzed by non- parametric tests. Categorical variables were described as frequency and percentage. The Pearson chi-squared test and Fisher's Exact test were used to test the associations between categorical variables. The Mann-Whitney test was used to assess differences in continuous variables between categories. All tests were 2-tailed. IBM SPSS Statistics for Windows, Version 25.0. Armonk, NY: IBM Corp. was used for all statistical analyses. A $p$ value $<0.05$ was considered statistically significant.

\section{Results}

Overall, among the 255 TMD patients, the female:male ratio was $3: 1$, and the mean age $\pm S D$ was $37 \pm 15.3$ years. The Axis I painful diagnoses were local myalgia in 114 patients $(44.7 \%)$, myofascial pain with referral in 83 patients (32.5\%), arthralgia in 50 patients (19.6\%), and HAattrTMD in 60 patients (23.5\%). The Axis II results showed that 42 patients (16.5\%) reported high levels of disability (GCPS levels 3-4), 20 (7.8\%) scored moderately severe-severe on the depression questionnaire (PHQ9), $13(5.1 \%)$ scored severe on the anxiety questionnaire (GAD-7), and $10(3.9 \%)$ scored severe on the nonspecific physical symptoms questionnaire (PHQ-15). 70 $(27.5 \%)$ of the patients reported persistent pain in the last 30 days.

In the first stage of the study, only patients with muscle-related disorders were included. They were divided into 1 group diagnosed as having local myalgia $(n=114)$ and a second group diagnosed as having myofascial pain with referral $(n=83)$. The demographic and socioeconomic characteristics of the 197-patient cohort are listed in Table 1 . The only significant difference between the 2 groups was income $(p=0.043)$. Only $5(6.3 \%)$ of the myofascial pain with referral group reported very lowlow income, compared to 18 (16.7\%) of the local myalgia group.

Table 2 presents the pain characteristics of the 2 study groups. There were no differences between them in pain duration $(p=0.217)$, headache duration $(p=0.295)$, and pain persistence score $(p=0.363)$. However, the myofascial pain with referral group reported significantly more headaches during the preceding 30 days $(p=0.002)$ and higher pain intensity $(p=0.033)$.

Table 3 presents the distribution of Axis I diagnoses in the 2 study groups. The only significant difference between them was a higher prevalence of the diagnosis of HAattrTMD in the myofascial pain with referral group $(p<0.001)$.

Table 4 lists the Axis II findings of both groups. Significant differences were found in the total scores for PHQ-9 (depression) $(p=0.006)$ and PHQ-15 (nonspecific physical symptoms; $p=0.001$ ), which were significantly higher in the myofascial pain with referral group. Significant differences were found in interference score $(p<0.001)$. The 2 groups did not differ in their disability scores [21 (18.8\%) patients in the local myalgia group had high scores in the category of disability (GCPS 3 and 4), compared to $17(20.5 \%)$ patients in the myofascial pain with referral group.] $(p=0.763)$.

In the second stage of the study, patients diagnosed with HAattrTMD were removed from both groups, and patients with myofascial pain with referral $(n=45)$ were compared with patients with local myalgia $(n=99)$. 
Table 1 Demographic and socioeconomic data of the 2 study groups (local myalgia vs. myofascial pain with referral)

\begin{tabular}{|c|c|c|c|}
\hline & Local myalgia & Myofascial pain with referral & $p$ \\
\hline Sex & & & 0.165 \\
\hline Male & $22(19.3 \%)$ & $23(27.7 \%)$ & \\
\hline Female & $92(80.7 \%)$ & $60(72.3 \%)$ & \\
\hline Age (years) & & & 0.813 \\
\hline$($ Mean \pm SD) & $39.00 \pm 16.73$ & $38.13 \pm 14.45$ & \\
\hline Median (IQR) & $32.50(25.75-51.00)$ & $34.00(28.00-52.00)$ & \\
\hline Education & & & 0.984 \\
\hline Elementary/high school & $38(33.6 \%)$ & $27(32.9 \%)$ & \\
\hline Some college/college graduate & $50(44.2 \%)$ & $36(43.9 \%)$ & \\
\hline Professional or post-graduate level & $25(22.1 \%)$ & $19(23.2 \%)$ & \\
\hline Income & & & 0.043 \\
\hline Very low, low & $18(16.7 \%)$ & $5(6.3 \%)$ & \\
\hline Average & $67(62.0 \%)$ & $49(61.3 \%)$ & \\
\hline High, very high & $23(21.3 \%)$ & $26(32.5 \%)$ & \\
\hline Marital status & & & 0.415 \\
\hline Never married & $46(40.7 \%)$ & $33(39.8 \%)$ & \\
\hline Married/living as married & $58(51.3 \%)$ & $47(56.6 \%)$ & \\
\hline Divorced/separated & $5(4.4 \%)$ & $3(3.6 \%)$ & \\
\hline Widowed & $4(3.5 \%)$ & $0(0 \%)$ & \\
\hline
\end{tabular}

*Significant values are shown in bold

Table 2 Pain characteristics of the 2 study groups (local myalgia vs. myofascial pain with referral)

\begin{tabular}{|c|c|c|c|}
\hline & Local myalgia & Myofascial pain with referral & $p$ \\
\hline \multicolumn{4}{|c|}{$\begin{array}{l}\text { Temporal characteristics: In the last } 30 \text { days, which of the following best describes any pain in your jaw, temple, in the ear, or in front of the ear on } \\
\text { either side? }\end{array}$} \\
\hline No pain & $5(4.5 \%)$ & $2(2.4 \%)$ & \multirow[t]{3}{*}{0.772} \\
\hline Pain comes and goes & $72(64.9 \%)$ & $52(63.4 \%)$ & \\
\hline Pain is always present & $34(30.6 \%)$ & $28(34.1 \%)$ & \\
\hline \multicolumn{4}{|c|}{ Pain duration: How many months ago did your pain in the jaw, temple, in the ear, or in front of the ear first begin? } \\
\hline$($ Mean $\pm S D)$ & $50.08 \pm 73.01$ & $61.03 \pm 93.93$ & \multirow[t]{2}{*}{0.217} \\
\hline Median (IQR) & $18.00(6.00-60.00)$ & $24.00(11.50-72.00)$ & \\
\hline \multicolumn{4}{|c|}{ Report of headache: In the last 30 days, have you had any headaches that included the temple areas of your head? } \\
\hline No & $53(46.9 \%)$ & $21(25.6 \%)$ & \multirow[t]{2}{*}{0.002} \\
\hline Yes & $60(53.1 \%)$ & $61(74.4 \%)$ & \\
\hline \multicolumn{4}{|c|}{ Headache duration: How many years or months ago did your temple headache first begin? } \\
\hline$($ Mean $\pm S D)$ & $62.73 \pm 77.58$ & $52.05 \pm 98.93$ & \multirow[t]{2}{*}{0.295} \\
\hline Median (IQR) & $27.00(4.25-96.00)$ & $24.00(3.00-60.00)$ & \\
\hline \multicolumn{4}{|c|}{ Characteristic Pain Intensity (CPI) (1-100) } \\
\hline Mean \pm SD) & $54.27 \pm 23.03$ & $60.9 \pm 21.74)$ & \multirow[t]{2}{*}{0.033} \\
\hline Median (IQR) & $53.33(40.00-70.00)$ & $66.67(43.33-80.00)$ & \\
\hline \multicolumn{4}{|c|}{ Pain persistence: On how many days in the last 6 months have you had facial pain? } \\
\hline$($ Mean \pm SD) & $80.16 \pm 76.44$ & $84.51 \pm 69.89$ & \multirow[t]{2}{*}{0.499} \\
\hline Median (IQR) & $30.00(13.25-180.00)$ & $60.00(20.00-180.00)$ & \\
\hline \multicolumn{4}{|l|}{ Pain Persistence Score: } \\
\hline Low ( $\leq 89$ days) & $58(60.4 \%)$ & $39(53.4 \%)$ & \multirow[t]{2}{*}{0.363} \\
\hline High ( $\geq 90$ days) & $38(39.6 \%)$ & $34(46.6 \%)$ & \\
\hline
\end{tabular}

*Significant values are shown in bold 
Table 3 Axis I diagnoses of the 2 study groups (local myalgia vs. myofascial pain with referral)

\begin{tabular}{lllr}
\hline & Local myalgia & $\begin{array}{l}\text { Myofascial } \\
\text { pain with } \\
\text { referral }\end{array}$ & \multicolumn{1}{c}{$\boldsymbol{p}$} \\
\hline Headache attributed to TMD & $15(13.2 \%)$ & $38(45.8 \%)$ & $<\mathbf{0 . 0 0 1}$ \\
Disc displacement & $43(37.7 \%)$ & $28(33.7 \%)$ & 0.565 \\
DJD & $18(15.8 \%)$ & $11(13.3 \%)$ & 0.620 \\
Arthralgia & $25(21.9 \%)$ & $18(21.7 \%)$ & 0.967 \\
Subluxation & $16(14.0 \%)$ & $9(10.8 \%)$ & 0.506 \\
\hline
\end{tabular}

*Significant values are shown in bold

Tables 5, 6 and 7 list the demographic, socioeconomic, pain characteristics, and Axis I findings in both groups. There were no differences between them for those parameters, including pain duration, pain levels, pain persistence, and all Axis I diagnoses.

Table 8 lists Axis II diagnoses in the 2 groups. After removing the patients diagnosed with HAattrTMD, total depression scores and total nonspecific physical symptoms scores remained significantly higher in the myofascial pain with referral group, although the level of significance was lower than the findings obtained for the first stage $(p=0.006$ compared to $p=0.033$ for the total depression score, and $p=0.001$ compared to $p=0.046$ for the total nonspecific physical symptoms score).

\section{Discussion}

The purpose of this study was to explore the differences between local myalgia and myofascial pain with referral as measured by the biopsychosocial model according to the DC/TMD. The results suggest that TMD patients diagnosed with myofascial pain with referral may have

Table 4 Axis II diagnoses of the 2 study groups (local myalgia vs. myofascial pain with referral)

\begin{tabular}{|c|c|c|c|c|}
\hline & & Local myalgia & Myofascial pain with referral & $p$ \\
\hline \multicolumn{5}{|l|}{ GCPS version 2.0} \\
\hline \multicolumn{2}{|l|}{ Low disability (GCPS 0-2) } & $91(81.3 \%)$ & $66(79.5 \%)$ & 0.763 \\
\hline \multicolumn{2}{|l|}{ High disability (GCPS 3-4) } & $21(18.8 \%)$ & 17 (20.5\%) & \\
\hline \multicolumn{5}{|l|}{ Interference score } \\
\hline \multicolumn{2}{|l|}{$($ Mean \pm SD) } & $24.62 \pm 30.25$ & $30.52 \pm 29.03$ & $<0.001$ \\
\hline \multicolumn{2}{|l|}{ Median (IQR) } & $10.00(0.00-36.66)$ & $20.00(6.66-50.00)$ & \\
\hline \multicolumn{5}{|l|}{ PHQ- 9 (Depression) } \\
\hline \multicolumn{2}{|l|}{ Normal } & $64(56.1 \%)$ & $35(42.2 \%)$ & \multirow[t]{4}{*}{0.258} \\
\hline Mild & $5-9$ & $32(28.1 \%)$ & $31(37.3 \%)$ & \\
\hline Moderate & $10-14$ & $9(7.9 \%)$ & $10(12.0 \%)$ & \\
\hline Moderately severe-severe & $15+$ & $9(7.9 \%)$ & $7(8.4 \%)$ & \\
\hline \multicolumn{5}{|l|}{ PHQ_-9 total score } \\
\hline \multicolumn{2}{|l|}{ (Mean \pm SD) } & $5.08 \pm 5.40$ & $6.61 \pm 5.15$ & 0.006 \\
\hline \multicolumn{2}{|l|}{ Median (IQR) } & $2.00(0.00-4.00)$ & $6.00(3.00-8.00)$ & \\
\hline \multicolumn{5}{|l|}{ GAD-7 (Generalized anxiety) } \\
\hline \multicolumn{2}{|l|}{ Normal } & $78(68.4 \%)$ & $47(56.6 \%)$ & \multirow[t]{4}{*}{0.272} \\
\hline Mild & $5-9$ & $21(18.4 \%)$ & $25(30.1 \%)$ & \\
\hline Moderate & $10-14$ & $9(7.9 \%)$ & $7(8.4 \%)$ & \\
\hline Severe & $15+$ & $6(5.3 \%)$ & $4(4.8 \%)$ & \\
\hline \multicolumn{5}{|l|}{ GAD- 7 total score } \\
\hline \multicolumn{2}{|l|}{$($ Mean $\pm S D)$} & $3.91 \pm 4.65$ & $4.66 \pm 4.71$ & \multirow[t]{2}{*}{0.113} \\
\hline \multicolumn{2}{|l|}{ Median (IQR) } & $2.00(0.00-6.00)$ & $4.00(1.00-7.00)$ & \\
\hline \multicolumn{5}{|c|}{ PHQ- 15 (Nonspecific physical symptoms) } \\
\hline Normal & $\leq 4$ & $63(55.3 \%)$ & $30(36.1 \%)$ & \multirow[t]{4}{*}{0.064} \\
\hline Mild & $5-9$ & $34(29.8 \%)$ & $37(44.6 \%)$ & \\
\hline Moderate & $10-14$ & $12(10.5 \%)$ & $12(14.5 \%)$ & \\
\hline Severe & $15+$ & $5(4.4 \%)$ & $4(4.8 \%)$ & \\
\hline \multicolumn{5}{|l|}{ PHQ- 15 total score } \\
\hline \multicolumn{2}{|l|}{$($ Mean $\pm S D)$} & $4.73 \pm 4.38$ & $6.47 \pm 4.24$ & \multirow[t]{2}{*}{0.001} \\
\hline Median (IQR) & & $4.00(1.00-7.00)$ & $6.00(4.00-9.00)$ & \\
\hline
\end{tabular}

*Significant values are shown in bold 
Table 5 Demographic and socioeconomic data of the 2 study groups (local myalgia vs. myofascial pain with referral excluding headache attributed to TMD)

\begin{tabular}{lcc}
\hline & $\begin{array}{c}\text { Local myalgia (Without } \\
\text { HAattrTMD) }\end{array}$ & $\begin{array}{c}\text { Myofascial pain with referral (Without } \\
\text { HAattrTMD) }\end{array}$ \\
\hline Sex & $19(19.2 \%)$ & $14(31.1 \%)$ \\
$\quad$ Male & $80(80.8 \%)$ & $31(68.9 \%)$ \\
$\quad$ Female & & \\
Age (years) & $40.11 \pm 17.27$ & $39.36 \pm 16.07$ \\
$\quad$ Mean \pm SD & $36.00(26.00-52.00)$ & $34.00(27.00-52.00)$ \\
Median (IQR) & & \\
Education & $31(31.6 \%)$ & $18(40.0 \%)$ \\
Elementary/high school & $45(45.9 \%)$ & $16(35.6 \%)$ \\
Some college/college graduate & $22(22.4 \%)$ & $11(24.4 \%)$ \\
Professional or post-graduate level & & $4(9.1 \%)$ \\
Income & $15(16.1 \%)$ & $30(68.2 \%)$ \\
Very low, low & $60(64.5 \%)$ & $10(22.7 \%)$ \\
Average & $18(19.4 \%)$ & $18(49.0 \%)$ \\
High, very high & & $26(57.8 \%)$ \\
Marital status & $37(37.8 \%)$ & $1(2.2 \%)$ \\
Never married & $52(53.1 \%)$ & $0(0 \%)$ \\
Married/living as married & $5(5.1 \%)$ & 0.947 \\
Divorced/separated & $4(4.1 \%)$ & 0.609 \\
Widowed & &
\end{tabular}

Table 6 Pain characteristics of the 2 study groups (local myalgia vs. myofascial pain with referral excluding headache attributed to TMD)

\section{Local myalgia (Without HAattrTMD) Myofascial pain with referral (Without $\quad p$ HAattrTMD)}

Temporal characteristics: In the last 30 days, which of the following best describes any pain in your jaw, temple, or ear?

$\begin{array}{lcc}\text { No pain } & 4(4.2 \%) & 2(4.5 \%) \\ \text { Pain comes and goes } & 66(68.8 \%) & 32(72.7 \%) \\ \text { Pain is always present } & 26(27.1 \%) & 10(22.7 \%)\end{array}$

0.892

Pain duration: How many months ago did your pain in the jaw, temple, in the ear, or in front of the ear first begin?
Mean \pm SD
$45.77 \pm 70.11$
$68.37 \pm 112.98$
Median (IQR)
$17.00(6.0-48.00)$
24 (11.00-72.00)

0.204

Report of headache: In the last 30 days, have you had any headaches that included the temple areas of your head?

$\begin{array}{lll}\text { No } & 53(54.1 \%) & 20(45.5 \%) \\ \text { Yes } & 45(45.9 \%) & 24(54.5 \%)\end{array}$

Headache duration: How many years or months ago did your temple headache first begin?
(Mean \pm SD)
$56.95 \pm 75.12$
Median (IQR)
$18.00(3.00-96.00)$
$52.65 \pm 137.22$
$12(2.00-36.00)$
Characteristic Pain Intensity (CPI) (1-100)

$\begin{array}{ll}\text { Mean } \pm \text { SD) } & 52.75 \pm 23.10 \\ \text { Median (IQR) } & 50.00(39.16-66.66)\end{array}$
$55.85 \pm 23.34$

0.459

Pain persistence: On how many days in the last 6 months have you had facial pain?
(Mean \pm SD)
$77.68 \pm 75.20$
$73.35 \pm 66.32$
Median (IQR)
$30.00(13.50-180.00)$
$50.00(20.00-120.00)$
Pain Persistence Score:

$\begin{array}{lll}\text { Low }(\leq 89 \text { days }) & 50(61.7 \%) & 25(62.5 \%) \\ \text { High }(\geq 90 \text { days }) & 31(38.3 \%) & 15(37.5 \%)\end{array}$

0.499 
Table 7 Axis I diagnoses of the 2 study groups (local myalgia vs. myofascial pain with referral excluding headache attributed to TMD)

\begin{tabular}{llll}
\hline & $\begin{array}{l}\text { Local myalgia } \\
\text { (Without } \\
\text { HAattrTMD) }\end{array}$ & $\begin{array}{l}\text { Myofascial pain with } \\
\text { referral (Without } \\
\text { HAattrTMD) }\end{array}$ & $\boldsymbol{p}$ \\
\hline Disc displacement & $36(36.4 \%)$ & $12(26.7 \%)$ & 0.253 \\
DJD & $18(18.2 \%)$ & $6(13.3 \%)$ & 0.469 \\
Arthralgia & $19(19.2 \%)$ & $10(22.2 \%)$ & 0.674 \\
Subluxation & $13(13.1 \%)$ & $5(11.1 \%)$ & 0.734 \\
\hline
\end{tabular}

a significant Axis II component. These results support the findings of a recent study by Barjandi et al. [17] that showed that TMD patients diagnosed with local myalgia scored significantly lower in the domains of depression, anxiety, somatic symptoms, pain catastrophizing, perceived stress, sick days, and insomnia compared to TMD patients diagnosed with myofascial pain with referral. Barjandi et al. [17] suggest therefore that a diagnosis of myofascial pain with referral could be indicative of a more severe condition compared to a diagnosis of local myalgia and may even point to a potential transition to fibromyalgia. It is the authors' belief that the findings of the current study demonstrate that using myalgia as the sole muscle-related diagnosis according to the DC/TMD without examining the subgroup diagnoses separately (i.e., local myalgia, and myofascial pain with referral) may be incomplete for clinical and research application.

Indeed, numerous studies have suggested that myofascial pain with referral results in the induction of central sensitization after ongoing peripheral nociceptive stimuli [25-28], implying the possibility of transference

Table 8 Axis II diagnoses of the 2 study groups (local myalgia vs. myofascial pain with referral excluding headache attributed to TMD)

\begin{tabular}{|c|c|c|c|c|}
\hline & & $\begin{array}{l}\text { Local myalgia (Without } \\
\text { HAattrTMD) }\end{array}$ & $\begin{array}{l}\text { Myofascial pain with referral (Without } \\
\text { HAattrTMD) }\end{array}$ & $p$ \\
\hline \multicolumn{5}{|l|}{ GCPS version 2.0} \\
\hline \multicolumn{2}{|l|}{ Low disability (GCPS 0-2) } & $81(83.5 \%)$ & $38(84.4 \%)$ & 0.888 \\
\hline \multicolumn{2}{|l|}{ High disability (GCPS 3-4) } & $16(16.5 \%)$ & $7(15.6 \%)$ & \\
\hline \multicolumn{5}{|l|}{ Interference score } \\
\hline \multicolumn{2}{|l|}{$($ Mean \pm SD) } & $22.50 \pm 29.03$ & $25.33 \pm 27.66$ & 0.221 \\
\hline \multicolumn{2}{|l|}{ Median (IQR) } & $10.00(0.00-33.33)$ & $16.66(3.33-40.00)$ & \\
\hline \multicolumn{5}{|l|}{ PHQ- 9 (Depression) } \\
\hline \multicolumn{2}{|l|}{ Normal } & $61(61.6 \%)$ & $21(46.7 \%)$ & \multirow[t]{4}{*}{0.376} \\
\hline Mild & $5-9$ & $24(24.2 \%)$ & $16(35.6 \%)$ & \\
\hline Moderate & $10-14$ & $7(7.1 \%)$ & 4 (8.9\%) & \\
\hline Moderately severe-severe & $15+$ & $7(7.1 \%)$ & 4 (8.9\%) & \\
\hline \multicolumn{5}{|l|}{ PHQ_-9 total score } \\
\hline \multicolumn{2}{|l|}{$($ Mean \pm SD) } & $4.71 \pm 5.34$ & $6.38 \pm 5.61$ & 0.033 \\
\hline \multicolumn{2}{|l|}{ Median (IQR) } & $3.00(1.00-7.00)$ & $6.00(2.00-8.00)$ & \\
\hline \multicolumn{5}{|l|}{ GAD-7 (Generalized anxiety) } \\
\hline \multicolumn{2}{|l|}{ Normal } & 69 (69.7\%) & $26(57.8 \%)$ & \multirow[t]{4}{*}{0.501} \\
\hline Mild & $5-9$ & $17(17.2 \%)$ & $12(26.7 \%)$ & \\
\hline Moderate & $10-14$ & $7(7.1 \%)$ & 4 (8.9\%) & \\
\hline Severe & $15+$ & $6(6.1 \%)$ & $3(6.7 \%)$ & \\
\hline \multicolumn{5}{|l|}{ GAD- 7 total score } \\
\hline \multicolumn{2}{|l|}{$($ Mean \pm SD) } & $3.85 \pm 4.78$ & $4.73 \pm 5.23$ & \multirow[t]{2}{*}{0.261} \\
\hline \multicolumn{2}{|l|}{ Median (IQR) } & $2.00(0.00-5.00)$ & $4.00(0.00-7.00)$ & \\
\hline \multicolumn{5}{|c|}{ PHQ- 15 (Nonspecific physical symptoms) } \\
\hline Normal & $\leq 4$ & $58(58.6 \%)$ & $20(44.4 \%)$ & \multirow[t]{4}{*}{0.385} \\
\hline Mild & $5-9$ & $28(28.3 \%)$ & $18(40.0 \%)$ & \\
\hline Moderate & $10-14$ & $10(10.1 \%)$ & $5(11.1 \%)$ & \\
\hline Severe & $15+$ & $3(3.0 \%)$ & $2(4.4 \%)$ & \\
\hline \multicolumn{5}{|l|}{ PHQ- 15 total score } \\
\hline \multicolumn{2}{|l|}{$($ Mean $\pm S D)$} & $4.34 \pm 4.20$ & $5.71 \pm 4.30$ & \multirow[t]{2}{*}{0.046} \\
\hline Median (IQR) & & $3.00(1.00-7.00)$ & $6.00(1.50-8.00)$ & \\
\hline
\end{tabular}

*Significant values are shown in bold 
to a chronic pain condition. There are also many studies that support an association between myofascial pain with referral and Axis II parameters [29-34]. Studies that have consistently shown that chronic TMD patients scored higher levels of Axis II on psychological questionnaires [35-38]. Moreover, prospective studies have shown that psychological variables predicted an increased risk for developing TMD [39, 40], and that the use of Axis II evaluation through the RDC/TMD for psychosocial assessment can aid in clinical decision making for the management of TMD [41].

Importantly, the current study demonstrated higher levels of Axis II irrespective of pain duration and pain intensity. This highlights that aside from pain duration and intensity other components contribute to persistence of TMD, such as genetic factors, environmental contributions, life stressors, autonomic function, and impaired pain regulation [42-44].

In the current study, the more widespread the pain (including HAattrTMD diagnosis) the more apparent were the differences in pain level, and the greater was the increase in the level of significance of the Axis II findings, including interference score which was higher in the myofascial pain with referral group which included patients with diagnosis of HAattrTMD. While no findings in disability levels and pain duration were found in the current study, it was previously shown that the diagnosis of HAattrTMD was associated with myofascial pain with referral, significantly higher Axis II results, greater disability, and higher pain levels, but no differences in pain duration compared to painful TMD patients without diagnosis of HAattrTMD [15]. These findings are consistent with those of others that associated widespread pain with significant Axis II components [41, 45, 46] and disability [47-49].Early identification of patients who are at a higher risk for developing chronic TMD may therefore aid in developing an effective tailored early intervention to reduce potential transference to a chronic condition.

The current study findings of significantly higher Axis II levels in the myofascial pain with referral group also raise the possibility of identifying potential future chronic TMD patients as early as the first visit with the sole use of Axis I findings of myofascial with referral according to the DC/TMD. This may be of significant clinical value, especially in situations where Axis II information is not available, and only Axis I information is used for diagnosis according to the DC/TMD $[18,19,50]$.

The current study could not answer the question of whether local myalgia and myofascial pain with referral represent different entities. As observed by Michelotti et al. [23], it is possible that both entities are presentations of a single disorder and therefore represent a continuum from mild and remittent local pain to more regional and continuous severe pain. On the other hand, it is possible that they are entirely separate disorders, a notion that is supported by others who believe that muscle-related TMD as a group encompasses a number of conditions [2]. It should be emphasized that the criterion validity of these muscular subgroups has not yet been established [5]. Future studies are needed in order to further examine the above hypotheses, especially those pertaining to findings that raise the possibility of transformation to a chronic pain disease.

\section{Conclusions}

The current study highlights the importance of differentiating between subgroups of myalgia according to the DC/TMD, specifically local myalgia and myofascial pain with referral, for both clinical and research purposes. The findings suggest that a diagnosis of myofascial pain with referral may be indicative of a significant Axis II component which may require a tailored treatment approach in order to try to prevent transference to a chronic pain condition. Finally, a higher score of an Axis II component may be expected in association with more widespread pain, including HAattrTMD.

\section{Abbreviations \\ DC/TMD: Diagnostic Criteria for Temporomandibular Disorders; HAattrTMD: Headache attributed to TMD; CPI: Characteristic pain intensity; TMD: Tempo- romandibular disorders; TMJs: Temporomandibular joints; RDC/TMD: Research Diagnostic Criteria/TMD; ICOP: International Classification of Orofacial Pain; PHQ: Patient Health Questionnaire; GAD: Generalized Anxiety Disorder; GCPS: Graded Chronic Pain Scale.}

\section{Acknowledgements}

The authors wish to thank Prof. Efraim Winocur for his important contribution to this study.

\section{Authors' contributions}

OWA, contributed to interpretation of data and writing the manuscript, PR contributed to conception, design, and data collection. KAR contributed to data collection and writing of the manuscript. LL contributed to writing the manuscript, critically revised the manuscript. AEP contributed to conception, design, and data collection. TG contributed to writing the manuscript, critically revised the manuscript. SR contributed to conception, data collection, design, writing of the manuscript. All authors read and approved the final manuscript.

Funding

The study was self -funded by the authors.

Availability of data and materials

The datasets used and/or analyzed during the current study is available from the corresponding author on reasonable request.

\section{Declarations}

\section{Ethics approval and consent to participate}

The study was approved by the Tel Aviv University Institutional Ethical Committee prior to data collection (\#14134_20180327) Informed consent for the study group was waived since the data were retrieved retrospectively.

Consent for publication

Not applicable. 


\section{Competing interests}

The authors declare that they have no competing interests.

\section{Author details}

${ }^{1}$ Department of Oral Pathology, Oral Medicine, and Maxillofacial Imaging, The Maurice and Gabriela Goldschleger School of Dental Medicine, Sackler Faculty of Medicine, Tel Aviv University, Tel Aviv, Israel. ${ }^{2}$ Department of Oral Rehabilitation, The Maurice and Gabriela Goldschleger School of Dental Medicine, Sackler Faculty of Medicine, Tel Aviv University, Tel Aviv, Israel. ${ }^{3}$ The Maurice and Gabriela Goldschleger School of Dental Medicine, Tel Aviv University, Tel Aviv, Israel. ${ }^{4}$ Department of Endodontics, The Maurice and Gabriela Goldschleger School of Dental Medicine, Sackler Faculty of Medicine, Tel Aviv University, Tel Aviv, Israel. ${ }^{5}$ Department of Physical Therapy, Recanati School for Community Health Professions, Faculty of Health Sciences, Ben-Gurion University of the Negev, Beer Sheva, Israel.

\section{Received: 23 October 2021 Accepted: 11 January 2022}

Published online: 04 February 2022

\section{References}

1. De Leeuw R, Klasser GD, editors. Orofacial pain: guidelines for assessment, diagnosis, and management. 6th ed. Chicago: Quintessence Publishing Co, Inc.; 2018

2. Stohler CS. Muscle-related temporomandibular disorders. J Orofac Pain. 1999;13:273-84

3. Anderson GC, Gonzalez YM, Ohrbach R, Truelove EL, Sommers E, Look JO, Schiffman EL. The Research Diagnostic Criteria for Temporomandibular Disorders. Vl: future directions. J Orofac Pain. 2010;24(1):79-88.

4. Schiffman E, Ohrbach R, Truelove E, Look J, Anderson G, Goulet JP, et al. Diagnostic Criteria for Temporomandibular Disorders (DC/TMD) for clinical and research applications: recommendations of the International RDC/TMD Consortium Network and Orofacial Pain Special Interest Group. J Oral Facial Pain Headache. 2014;28:6-27.

5. Schiffman E, Ohrbach R. Executive summary of the Diagnostic Criteria for Temporomandibular Disorders for clinical and research applications. J Am Dent Assoc. 2016;147(6):438-45.

6. Bron C, Dommerholt JD. Etiology of myofascial trigger points. Curr Pain Headache Rep. 2012;16(5):439-44.

7. Shah JP, Thaker N, Heimur J, Aredo JV, Sikdar S, Gerber L. Myofascial trigger points then and now: a historical and scientific perspective. PM R. 2015;7(7):746-61.

8. Quintner JL, Bove GM, Cohen ML. A critical evaluation of the trigger point phenomenon. Rheumatology (Oxford). 2015;54(3):392-9.

9. Fernández-de-las-Peñas C, Dommerholt J. Myofascial trigger points: peripheral or central phenomenon? Curr Rheumatol Rep. 2014;16(1):395.

10. Hotfiel T, Freiwald J, Hoppe MW, Lutter C, Forst R, Grim C, Bloch W, Hüttel M, Heiss R. Advances in delayed-onset muscle soreness (DOMS): part I: pathogenesis and diagnostics. Sportverletz Sportschaden. 2018:32(4):243-50.

11. Mense $S$. The pathogenesis of muscle pain. Curr Pain Headache Rep. 2003;7(6):419-25

12. Takeuchi T, Arima T, Ernberg M, Yamaguchi T, Ohata N, Svensson P. Symptoms and physiological responses to prolonged, repeated, low-level tooth clenching in humans. Headache. 2015;55(3):381-94.

13. Chen CY, Palla S, Erni S, Sieber M, Gallo LM. Nonfunctional tooth contact in healthy controls and patients with myogenous facial pain. J Orofac Pain. 2007;21(3):185-93.

14. International classification of orofacial pain, 1st edn (ICOP). Cephalalgia. 2020:40(2):129-221

15. Reiter S, Emodi-Perlman A, Kasiel H, Abboud W, Friedman-Rubin P, Winocur-Arias O, Manor Y. Headache attributed to Temporomandibular Disorders: Axis I and II findings according to the Diagnostic Criteria for Temporomandibular Disorders. J Oral Facial Pain Headache. 2021;35(2):119-28. https://doi.org/10.11607/ofph.2863

16. Mijiritsky E, Winocur E, Emodi-Perlman A, Friedman-Rubin P, Dahar E, Reiter S. Tinnitus in Temporomandibular Disorders: Axis I and Axis II findings according to the Diagnostic Criteria for Temporomandibular Disorders. J Oral Facial Pain Headache. 2020;34(3):265-72.
17. Barjandi G, Kosek E, Hedenberg-Magnusson B, Velly AM, Ernberg M. Comorbid conditions in Temporomandibular Disorders myalgia and myofascial pain compared to fibromyalgia. J Clin Med. 2021;10(14):3138.

18. Montes-Carmona JF, Gonzalez-Perez LM, Infante-Cossio P. Treatment of localized and referred masticatory myofascial pain with botulinum toxin injection. Toxins (Basel). 2020;13(1):6.

19. Abboud WA, Hassin-Baer S, Joachim M, Givol N, Yahalom R. Localized myofascial pain responds better than referring myofascial pain to botulinum toxin injections. Int J Oral Maxillofac Surg. 2017;46(11):1417-23.

20. Pietropaoli D, Ortu E, Giannoni M, Cattaneo R, Mummolo A, Monaco A. Alterations in surface electromyography are associated with subjective masticatory muscle pain. Pain Res Manag. 2019;22(2019):6256179.

21. Broberg K, Lindskog-Stokland B, Mejersjö C. Anterior bite opening in adulthood. Open Dent J. 2017;13(11):628-35.

22. Schiffman $E$, Ohrbach $R$. The many faces of persistent orofacial muscle pain—authors response. J Oral Facial Pain Headache. 2015;29(2):208.

23. Michelotti A, Alstergren P, Goulet JP, Lobbezoo F, Ohrbach R, Peck C, Schiffman E, List T. Next steps in development of the Diagnostic Criteria for Temporomandibular Disorders (DC/TMD): recommendations from the International RDC/TMD Consortium Network workshop. J Oral Rehabil. 2016;43(6):453-67.

24. Ohrbach R (Editor). Diagnostic Criteria for Temporomandibular Disorders: Assessment Instruments (HEBREW). Version 15May 2016. Hebrew version by: Reiter S, Winocur E, Akrish S, et al.

25. Fernández-de-Las-Peñas C. Myofascial head pain. Curr Pain Headache Rep. 2015;19(7):28.

26. Xu YM, Ge HY, Arendt-Nielsen L. Sustained nociceptive mechanical stimulation of latent myofascial trigger point induces central sensitization in healthy subjects. J Pain. 2010;11:1348-55.

27. Niddam DM, Chan RC, Lee SH, et al. Central representation of hyperalgesia from myofascial trigger point. Neuroimage. 2008;39:1299-306.

28. Niddam DM. Brain manifestation and modulation of pain from myofascial trigger points. Curr Pain Headache Rep. 2009;13:370-5.

29. Gerber LH, Sikdar S, Armstrong K, Diao G, Heimur J, Kopecky J, Turo D, Otto P, Gebreab T, Shah J. A systematic comparison between subjects with no pain and pain associated with active myofascial trigger points. PM R. 2013;5(11):931-8.

30. Muñoz-Muñoz S, Muñoz-García MT, Alburquerque-Sendín F, ArroyoMorales M, Fernández-de-las-Peñas C. Myofascial trigger points, pain, disability, and sleep quality in individuals with mechanical neck pain. J Manip Physiol Ther. 2012;35(8):608-13.

31. Iglesias-González JJ, Muñoz-García MT, Rodrigues-de-Souza DP, Alburquerque-Sendín F, Fernández-de-Las-Peñas C. Myofascial trigger points, pain, disability, and sleep quality in patients with chronic nonspecific low back pain. Pain Med. 2013;14(12):1964-70.

32. Altindag $O$, Gur A, Altindag A. The relationship between clinical parameters and depression level in patients with myofascial pain syndrome. Pain Med. 2008;9(2):161-5.

33. Esenye M, Caglar N, Aldemir T. Treatment of myofascial pain. Am J Phys Med Rehabil. 2000;79:48-52.

34. Gur A, Sarac AJ, Cevik R, Altindag O, Sarac S. Efficacy of 904 nm gallium arsenide low level laser therapy in the management of chronic myofascial pain in the neck: a double-blind and randomize-controlled trial. Lasers Surg Med. 2004;3:229-35.

35. Schumann NP, Zwiener U, Nebrich A. Personality and quantified neuromuscular activity of the masticatory system in patients with temporomandibular joint dysfunction. J Oral Rehabil. 1988;15(1):35-47.

36. Rudy TE, Turk DC, Zaki HS, Curtin HD. An empirical taxometric alternative to traditional classification of temporomandibular disorders. Pain. 1989;36(3):311-20.

37. Etscheidt MA, Steger HG, Braverman B. Multidimensional Pain Inventory profile classifications and psychopathology. J Clin Psychol. 1995;51(1):29-36

38. Dworkin SF, LeResche L. Research Diagnostic Criteria for Temporomandibular Disorders: review, criteria, examinations and specifications, critique. J Craniomandib Disord. 1992;6(4):301-55.

39. Fillingim RB, Ohrbach R, Greenspan JD, Knott C, Diatchenko L, Dubner R, Bair E, Baraian C, Mack N, Slade GD, Maixner W. Psychological factors associated with development of TMD: the OPPERA prospective cohort study. J Pain. 2013;14(12 Suppl):T75-90. 
40. Von Korff M, Resche LL, Dworkin SF. First onset of common pain symptoms: a prospective study of depression as a risk factor. Pain. 1993;55(2):251-8.

41. Dworkin SF, Huggins KH, Wilson L, Mancl L, Turner J, Massoth D, LeResche $\mathrm{L}$, Truelove E. A randomized clinical trial using research Diagnostic Criteria for Temporomandibular Disorders-Axis II to target clinic cases for a tailored self-care TMD treatment program. J Orofac Pain. 2002;16(1):48-63.

42. Smith SB, Maixner DW, Greenspan JD, Dubner R, Fillingim RB, Ohrbach R, Knott C, Slade GD, Bair E, Gibson DG, Zaykin DV, Weir BS, Maixner W, Diatchenko L. Potential genetic risk factors for chronic TMD: genetic associations from the OPPERA case control study. J Pain. 2011;12(11 Suppl):T92-101.

43. Yarnitsky D. Conditioned pain modulation (the diffuse noxious inhibitory control-like effect): its relevance for acute and chronic pain states. Curr Opin Anaesthesiol. 2010;23(5):611-5.

44. Maixner W, Diatchenko L, Dubner R, Fillingim RB, Greenspan JD, Knott C, Ohrbach R, Weir B, Slade GD. Orofacial pain prospective evaluation and risk assessment study —-the OPPERA study. J Pain. 2011;12(11 Suppl):T4-11.e1-T4-11.e2.

45. Raphael KG, Marbach JJ, Klausner J. Myofascial face pain: clinical characteristics of those with regional vs. widespread pain. J Am Dent Assoc. 2000;131(2):161-71.

46. Velly A, List T, Lobbezoo F. Comorbid pain and psychological conditions in patients with orofacial pain. In: Sessle BJ, editor. Orofacial pain: recent advances in assessment, management, and understanding of mechanisms. Washington: IASP Press; 2014. p. 53-73.

47. John MT, Miglioretti DL, LeResche L, Von Korff M, Critchlow CW. Widespread pain as a risk factor for dysfunctional temporomandibular disorder pain. Pain. 2003;102(3):257-63.

48. Gerdle B, Björk J, Cöster L, Henriksson K, Henriksson C, Bengtsson A. Prevalence of widespread pain and associations with work status: a population study. BMC Musculoskelet Disord. 2008;15(9):102.

49. Grimby-Ekman A, Gerdle B, Björk J, Larsson B. Comorbidities, intensity, frequency and duration of pain, daily functioning and health care seeking in local, regional, and widespread pain-a descriptive population-based survey (SwePain). BMC Musculoskelet Disord. 2015;24(16):165.

50. Young A, Gallia S, Ryan JF, Kamimoto A, Korczeniewska OA, Kalladka M, Khan J, Noma N. Diagnostic tool using the Diagnostic Criteria for Temporomandibular Disorders: a randomized crossover-controlled, doubleblinded, two-center study. J Oral Facial Pain Headache. 2021;35(3):241-52.

\section{Publisher's Note}

Springer Nature remains neutral with regard to jurisdictional claims in published maps and institutional affiliations.

Ready to submit your research? Choose BMC and benefit from:

- fast, convenient online submission

- thorough peer review by experienced researchers in your field

- rapid publication on acceptance

- support for research data, including large and complex data types

- gold Open Access which fosters wider collaboration and increased citations

- maximum visibility for your research: over 100M website views per year

At BMC, research is always in progress.

Learn more biomedcentral.com/submissions 